\title{
Research on Inhibiting Performance of Compound Corrosion Inhibitors Based on Nitrite
}

\author{
Bing Yi $\mathbb{D}^{1},{ }^{1}$ Jianmin Wang $\mathbb{D}^{1},{ }^{1}$ Liyu Feng $\mathbb{D},{ }^{1}$ Yilin Song $\mathbb{D},{ }^{1}$ Junzhe Liu $\mathbb{D},{ }^{2}$ \\ and Haibin Shu $\mathbb{D}^{1}$ \\ ${ }^{1}$ School of Civil and Environmental Engineering, Ningbo University, Ningbo 315211, China \\ ${ }^{2}$ College of Civil Engineering \& Architecture, Qingdao Agricultural University, Qingdao 266109, China
}

Correspondence should be addressed to Junzhe Liu; junzheliu@163.com

Received 23 December 2020; Revised 25 February 2021; Accepted 9 March 2021; Published 23 March 2021

Academic Editor: Zhigang Zhang

Copyright (c) 2021 Bing Yi et al. This is an open access article distributed under the Creative Commons Attribution License, which permits unrestricted use, distribution, and reproduction in any medium, provided the original work is properly cited.

\begin{abstract}
To solve rebar corrosion in existing concrete structures, two test methods, adding corrosion inhibitors into concrete and applying corrosion inhibitors on the existing concrete surface by brushing and pouring and composite repair, combined with natural potential, XRD and SEM, were used to comprehensively evaluate the performance of nitrite-based compound corrosion inhibitors. The research results show that nitrite has a better inhibitory effect than phosphate, and when the respective mass fraction of hydrogen phosphate and sodium nitrite is about $1.5 \%$, the rust inhibition effect is the optimum. Brushing, perfusion, and composite repair can all play a good role in inhibiting corrosion of which composite repair is the best. The addition of phosphate can improve the macrocell corrosion caused by the low dosage or uneven distribution of nitrite.
\end{abstract}

\section{Introduction}

Concrete is the most widely used engineering material in construction, and its durability has attracted widespread attention worldwide [1-3]. Concrete constructions are applied in the complex environment when serving in coastal areas, including freeze-thaw, long-term immersion and dry and wet alternation of the salt solution by seawater, carbonization, and their coupling effects [4-6]. Of all conditions, corrosion of rebars caused by chloride is a major cause of premature failure of concrete structures [7-10]. Scholars have found that electrochemical chloride removal (ECR) can remove the chloride in concrete structures without damage and, effectively, strengthen the concrete strength and established related models [11-13]. The use of corrosion inhibitors is also an economical and practical means to improve the durability of concrete structures [14-17]. Studies have found that nitrite as a cathodic rust inhibitor is characterized by good corrosion resistance effect, but will aggravate the macrocell corrosion at low concentration, and phosphate as a cathodic corrosion inhibitor is not as effective as nitrite, but will not accelerate corrosion due to low concentration or uneven distribution [18-21]. Compound corrosion inhibitors can combine the advantages of each component and overcome the disadvantages of a single component, which have a better inhibitory corrosion effect of steel bars at a reasonable amount [22-26].

On the premise of ensuring the effect of corrosion inhibition, the optimum ratio and dosage of compound corrosion inhibitor are determined by nitrite and phosphate. And, two test methods, adding corrosion inhibitors to concrete and applying corrosion inhibitors on the existing concrete surface by brushing and pouring and composite repair, combined with natural potential, XRD and SEM, were used to comprehensively evaluate the performance of nitrite-based compound corrosion inhibitors, provide a theoretical basis for improving the durability and service life of reinforced concrete structures, and provide a new research idea for the combination of composite corrosion inhibitors and ECR to mitigate chloride penetration. 


\section{Materials and Methods}

2.1. Material Preparation. In this research, sodium nitrite $\left(\mathrm{NaNO}_{2}\right)$ and disodium hydrogen phosphate $\left(\mathrm{NaH}_{2} \mathrm{PO}_{4}\right)$ with purity higher than $99.9 \%$ were applied as rust inhibitors. Ordinary Portland cement whose strength grade was $42.5 \mathrm{MPa}$ and grade HPB300 plain round steel bars with a diameter of $10 \mathrm{~mm}$ were used in experiments. The mix ratio of the concrete specimen with the size of $100 \mathrm{~mm} \times 100 \mathrm{~mm} \times 400 \mathrm{~mm}$ and the thickness of the steel protection layer is $20 \mathrm{~mm}$, which is shown in Table 1 . The mixing ratio of the $2 \% \mathrm{NaCl}$-incorporated rust inhibitor test pieces is shown in Table 2. Test the spontaneous potential of the steel bar every month for 12 months after curing for 28 days under standard conditions. The concrete specimens were split and taken out of the steel bars to determine the corroded area ratio and weight loss ratio by JCISC1 standard after 12 months [25]. Besides, four sets of external rust inhibitor test pieces serially numbered 1 to 4 and the $\mathrm{NaCl}$ content $0.01 \%, 0.03 \%, 0.06 \%$, and $0.1 \%$ of the sand mass were prepared to simulate the existing structural concrete in a chloride salt erosion environment. The specific content of each group is shown in Table 3.

The existing concrete structure was selected from the two embankments of Daxie Island Pier, Ningbo, where the steel bar had corroded. The chloride ion concentration, spontaneous potential, and corrosion current of the repair surface were measured after brushing and composite repair.

\subsection{Experiment Method}

2.2.1. Brushing, Infusion, and Composite Repair. After curing for 28 days under standard conditions, brush the polished concrete test piece with $50 \mathrm{ml}$ of $70 \% \mathrm{NaNO}_{2}$ solution every four hours for three times. Three low-pressure pouring machines with $50 \mathrm{ml}$ corrosion inhibitor were placed on the quarter point of the concrete samples. Similarly, for the compound repair, the perfusion was performed after brushing. After 30 days, the repaired specimens were placed in a curing chamber at $20^{\circ} \mathrm{C}$ and $60 \%$ relative humidity and the potential of the steel bars per month was measured, which lasts for a year.

Apply $2500 \mathrm{ml} / \mathrm{m}^{2}$ of $70 \% \mathrm{NaNO}_{2}$ solution to the first existing engineering repaired surface repeatedly every hour. For the second repair surface, the $70 \% \mathrm{NaNO}_{2}$ solution of $1250 \mathrm{ml} / \mathrm{m}^{2}$ was applied repeatedly every hour. After the application, the perfusion devices with $1250 \mathrm{ml} / \mathrm{m}^{2}$ $\mathrm{Na}_{2} \mathrm{HPO}_{4}$ solution were placed at an interval of $15 \mathrm{~cm}$ along the steel bar and the potential and corrosion current was measured every 3 months after repair.

2.2.2. Potential Detection. The potential is measured according to ASTMC876 [27], and the evaluation criteria are shown in Table 4.

2.2.3. Analysis of the Micromechanism of the Compound Corrosion Inhibitor. XRD analysis: the concrete samples cured for one month were split, and a small amount of cement paste bonded to steel bars was taken out. A powder with a size less than $0.3 \mathrm{~mm}$ was obtained. Bake in an oven at $60 \pm 5^{\circ} \mathrm{C}$ for 24 hours. After drying, put in plastic sample bags and seal it. The D8 ADVANCE X-ray diffractometer produced by Bruker AXS was used for phase analysis and quantitative analysis of the prepared samples.

Scanning electron microscopy analysis: the concrete test samples cured for one month were knocked into fragments with a particle size of about $5 \mathrm{~mm}$, and a certain amount of the fragments is put into an oven and dried at $60 \pm 5^{\circ} \mathrm{C}$ for $24 \mathrm{~h}$. After cooling, these were placed and sealed in plastic sample bags. Scanning for the structure occurred using a SU70 field emission scanning electron microscope.

\section{Results and Discussion}

3.1. Effect of Rust Inhibitor Mixed with Concrete. Figures 1 and 2 show the potential of reinforcement in the concrete specimens with different concentrations of $\mathrm{NaNO}_{2}$ and $\mathrm{Na}_{2} \mathrm{HPO}_{4}$. It can be seen that the potential continues to decrease faster than the blank sample when the proportion of $\mathrm{NaNO}_{2}$ is only $0.5 \%$, and the potential will be stable with the increase of $\mathrm{NaNO}_{2}$. When the proportion of $\mathrm{NaNO}_{2}$ reaches $2.0 \%$, the steel bar is in a passive state which will be not corrosive. This is attributed to the fact that nitrite is anode corrosion inhibitor, which can oxidize the ionized $\mathrm{Fe}^{2+}$ to $\mathrm{Fe}_{2} \mathrm{O}_{3}$ through the strong oxidation of $\mathrm{NO}_{2}{ }^{-}$, which attach to the surface of steel and form a dense passive film, thus inhibiting the occurrence of anode reaction and preventing the further loss of electrons of iron atoms [28]. However, when the proportion of nitrite is insufficient, the steel surface cannot be completely passivated, and the corrosion is concentrated in the unpassivated area. As the cathode, the area of the passivated area is greatly increased, while the anode area of the unpassivated area is relatively reduced, which increases the current density of the anode area, leads to the macrocell corrosion, and deepens the pitting corrosion of steel bars.

It can be inferred that the pitting corrosion does not occur like nitrite when phosphate at low content as a cathodic rust inhibitor. As the content of $\mathrm{Na}_{2} \mathrm{HPO}_{4}$ increases, the potential rises slowly, but the rust-inhibiting effect is not as well as $\mathrm{NaNO}_{2}$. The general view is that $\mathrm{HPO}_{4}{ }^{2-}$ and $\mathrm{Ca}(\mathrm{OH})_{2}$ in the pore solution of concrete form hydroxyapatite to block the pores in concrete, or $\mathrm{PO}_{3}{ }^{-}$hydrolyzed by $\mathrm{HPO}_{4}{ }^{2-}$ reacts with $\mathrm{Fe}^{2+}$ on the surface of steel bars to form a layer of iron phosphate film to prevent $\mathrm{Cl}^{-}$from invading [29].

It can be seen from Figure 3 that compared to the single doping of $\mathrm{NaNO}_{2}$, the spontaneous potential of the compound doping with $\mathrm{NaNO}_{2}$ and $\mathrm{Na}_{2} \mathrm{HPO}_{4}$ increases significantly, which shows better corrosion resistance. With the increase of $\mathrm{Na}_{2} \mathrm{HPO}_{4}$, the probability of steel corrosion decreases significantly. Meanwhile, with the same percentage of $\mathrm{NaNO}_{2}$, changing the percentage of $\mathrm{Na}_{2} \mathrm{HPO}_{4}$ does not alter the potential significantly. Therefore, the amount of $\mathrm{Na}_{2} \mathrm{HPO}_{4}$ cannot play a determined role in the corrosion resistance effect.

Figure 4 and 5 compare the corroded area rate and mass loss rate of the steel bars in the specimens with different corrosion inhibitors. When $\mathrm{NaNO}_{2}$ has been added alone, the corrosion area rate and mass loss rate increase first and then decrease rapidly with the increase of the amount of 
TABLE 1: Mix proportion of concrete.

\begin{tabular}{lcccccc}
\hline & Dosage per unit volume $\left(\mathrm{kg} / \mathrm{m}^{3}\right)$ & & \multicolumn{2}{c}{ Mix parameter } \\
\hline Cement & Sand & Stone & Water & Sand ratio (\%) & Slump (cm) & Gas content (\%) \\
300 & 760 & 1080 & 120 & 41 & 16 & 4 \\
\hline
\end{tabular}

TABLE 2: Compound proportion of corrosion inhibitors (\%).

\begin{tabular}{|c|c|c|c|c|c|}
\hline & Number & Volume & & Number & Volume \\
\hline \multirow{5}{*}{$\mathrm{NaNO}_{2}$} & N1 & 0.5 & \multirow{5}{*}{$\mathrm{Na}_{2} \mathrm{HPO}_{4}$} & $\mathrm{P} 1$ & 0.5 \\
\hline & N2 & 1.0 & & $\mathrm{P} 2$ & 1.0 \\
\hline & N3 & 1.5 & & P3 & 1.5 \\
\hline & N4 & 2.0 & & $\mathrm{P} 4$ & 2.0 \\
\hline & N5 & 2.5 & & P5 & 2.5 \\
\hline \multirow{5}{*}{ Composite } & A1 & $0.5+1.5$ & \multirow{5}{*}{ Composite } & $\mathrm{C} 1$ & $1.5+0.5$ \\
\hline & A2 & $0.5+2.0$ & & $\mathrm{C} 2$ & $1.5+1.0$ \\
\hline & B1 & $1.0+1.0$ & & $\mathrm{C} 3$ & $1.5+1.5$ \\
\hline & B2 & $1.0+1.5$ & & D1 & $2.0+0.5$ \\
\hline & B3 & $1.0+2.0$ & & D2 & $2.0+1.0$ \\
\hline
\end{tabular}

Note: another blank control group, BLK, is not added with the corrosion inhibitor.

TABle 3: Proportion of corrosion inhibitor in repairing test.

\begin{tabular}{lccc}
\hline & Number & Corrosion inhibitor & Dosage/ml \\
\hline Brush repair & $\mathrm{E}$ & $\mathrm{NaNO}_{2}$ & 150 \\
\hline \multirow{2}{*}{ Perfusion repair } & $\mathrm{F}$ & $\mathrm{NaNO}_{2}$ & 150 \\
& $\mathrm{G}$ & $\mathrm{Na}_{2} \mathrm{HPO}_{4}$ & 150 \\
\hline \multirow{2}{*}{ Composite repair } & $\mathrm{H}$ & $\mathrm{NaNO}_{2}$ & 75 \\
& & $\mathrm{Na}_{2} \mathrm{HPO}_{4}$ & 75 \\
\hline
\end{tabular}

Note: another blank control group, I, is not added with the corrosion inhibitor.

TABLE 4: Evaluation criteria for corrosion of the steel bar.

\begin{tabular}{lc}
\hline Potential/mV & Corrosion probability \\
\hline$E>-200 \mathrm{mV}$ & Less than $10 \%$ \\
$-200 \mathrm{mV}>E>-350 \mathrm{mV}$ & Not sure \\
$E<-350 \mathrm{mV}$ & More than $90 \%$ \\
\hline
\end{tabular}

$\mathrm{NaNO}_{2}$. After reaching $2.0 \%$, the corrosion area ratio is less than $12 \%$ and the mass loss rate is less than $10 \%$. It means the corrosion is almost inhibited, indicating that $\mathrm{NaNO}_{2}$ has good corrosion resistance. However, it will accelerate the corrosion when the amount of $\mathrm{NaNO}_{2}$ is insufficient. The corrosion area ratio decreases from more than $50 \%$ to about $20 \%$ and the mass loss ratio also decreases from more than $35 \%$ to $20 \%$ after the assembly unit of $\mathrm{NaNO}_{2}$ and $\mathrm{Na}_{2} \mathrm{HPO}_{4}$. The higher the $\mathrm{NaNO}_{2}$ concentration is, the more obvious is the effect of compounding $\mathrm{Na}_{2} \mathrm{HPO}_{4}$ on improving the corroded area rate and mass loss rate. Compared with groups of B2, B3, C2, C3, and D2, it can be found that when the respective content of $\mathrm{NaNO}_{2}$ and $\mathrm{Na}_{2} \mathrm{HPO}_{4}$ is between $1.0 \%$ and $2.0 \%$, the corrosion area rate drops below $3 \%$ and the weight loss rate drops below $1 \%$, indicating that the steel bars are hardly corroded. Combined with the proportion and effect, it can be found that the comprehensive inhibitory effect is the best when the respective proportion of $\mathrm{NaNO}_{2}$ and $\mathrm{Na}_{2} \mathrm{HPO}_{4}$ is about $1.5 \%$.

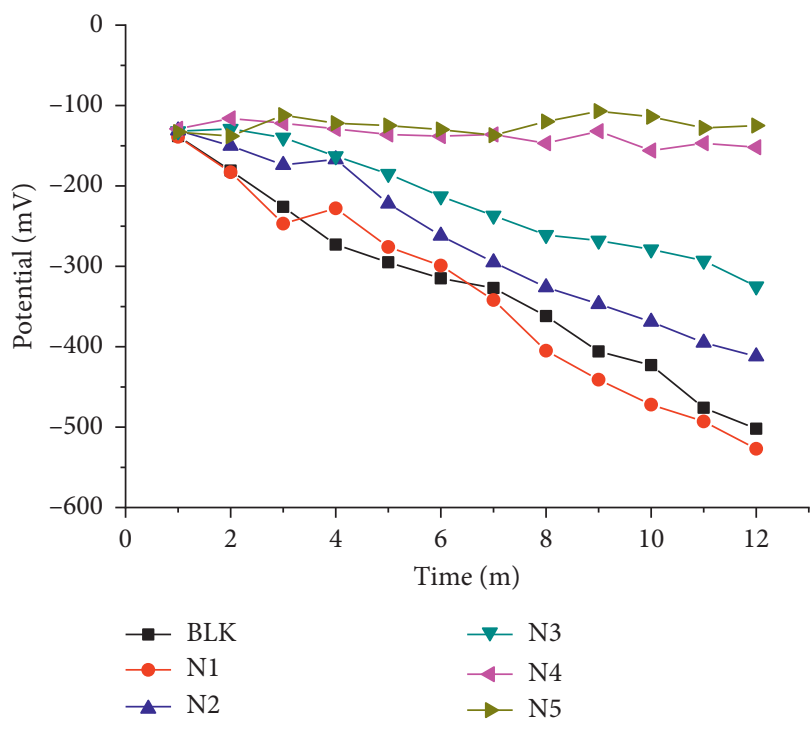

Figure 1: Corrosion inhibitor of $\mathrm{NaNO}_{2}$.

3.2. Influence of Corrosion Inhibitor on the Microstructure of Concrete. Figure 6 compares the differences of cement hydration products in concrete samples with various corrosion inhibitors. The proportion of $\mathrm{CaCO}_{3}$, ettringite (AFt), and $\mathrm{CaSO}_{4} \cdot 2 \mathrm{H}_{2} \mathrm{O}$ is significantly lower than that of the 


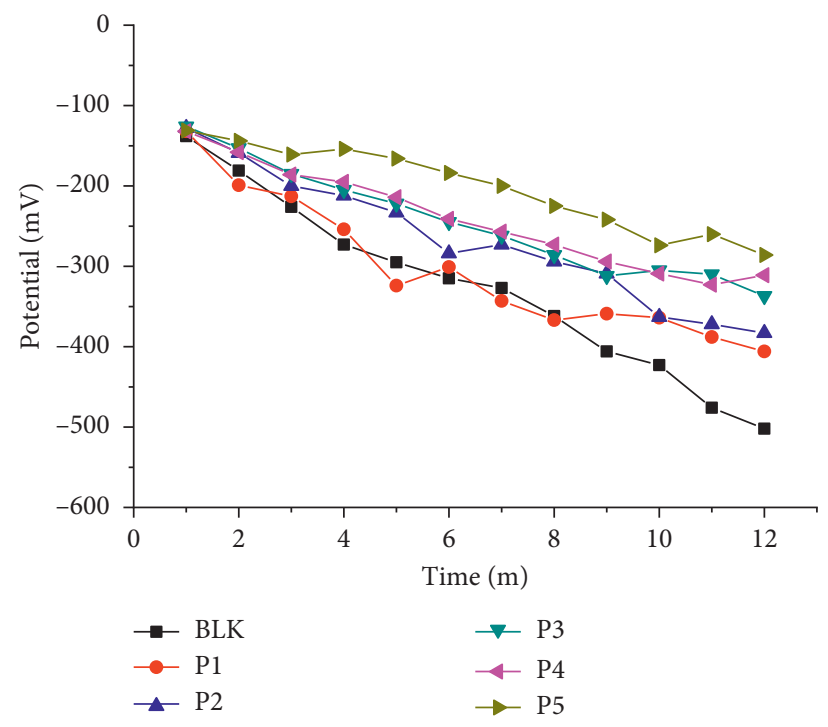

FIgURE 2: Corrosion inhibitor of $\mathrm{Na}_{2} \mathrm{HPO}_{4}$.

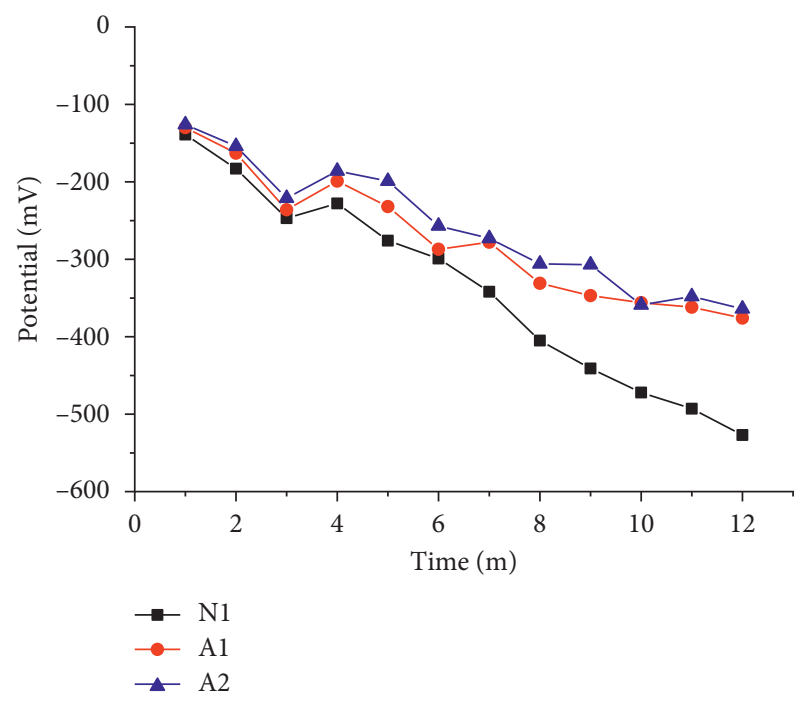

(a)

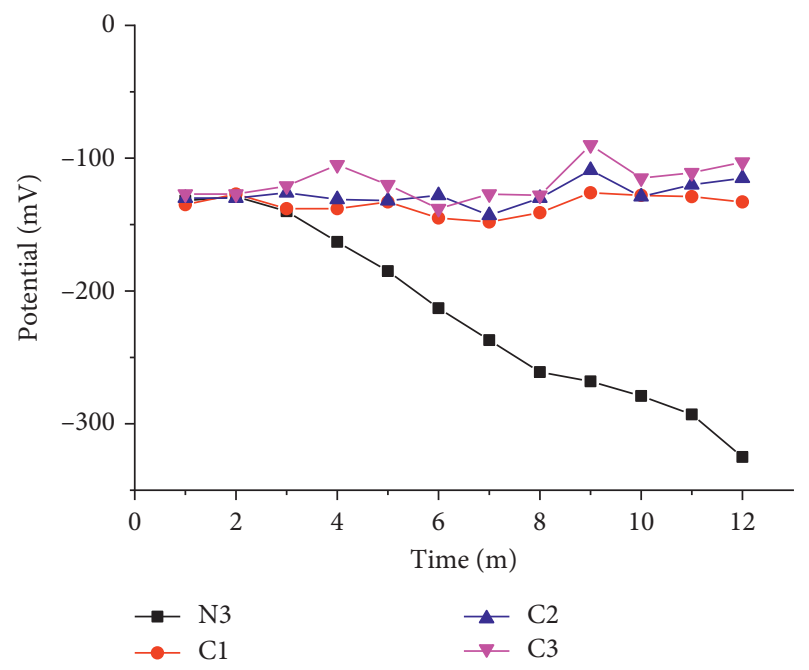

(c)

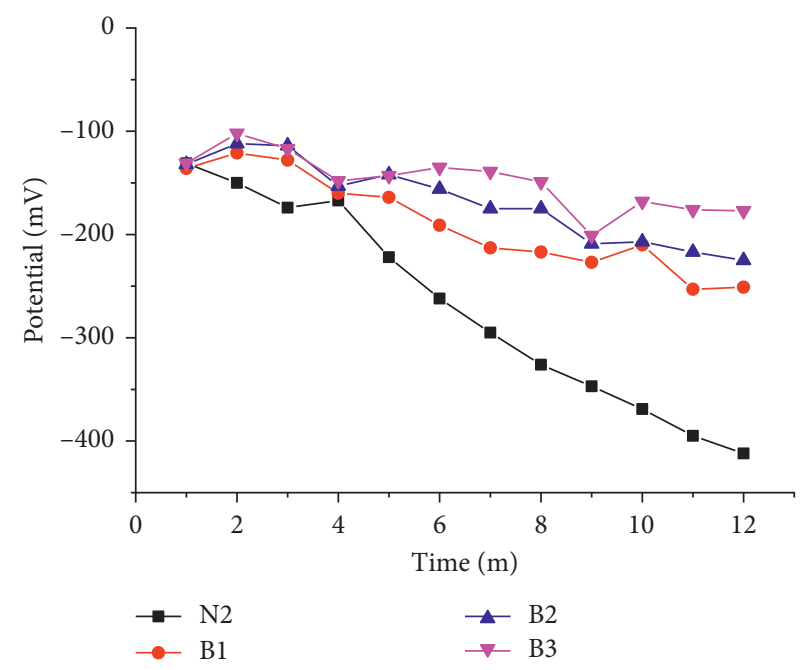

(b)

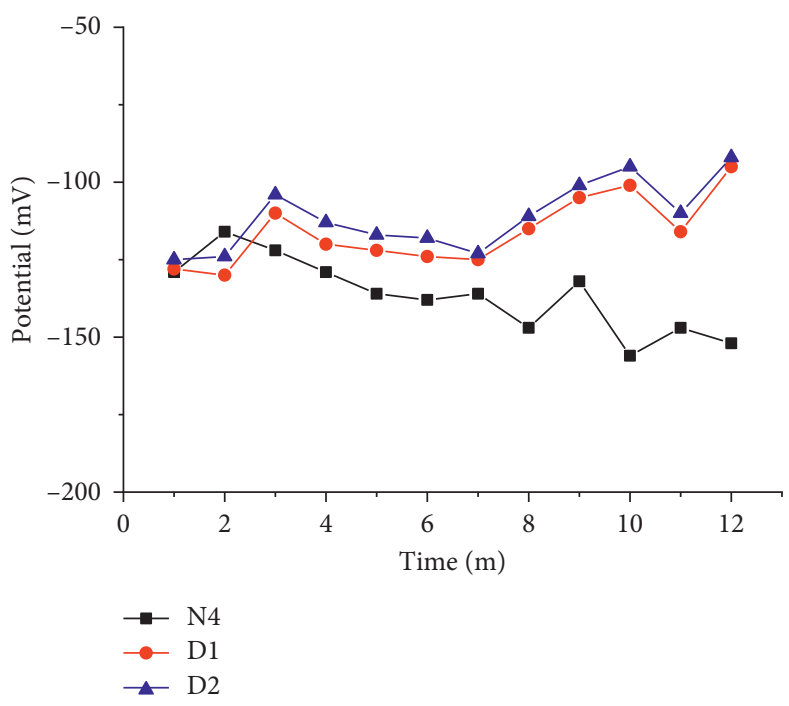

(d)

FIGURE 3: Composite corrosion inhibitor. 


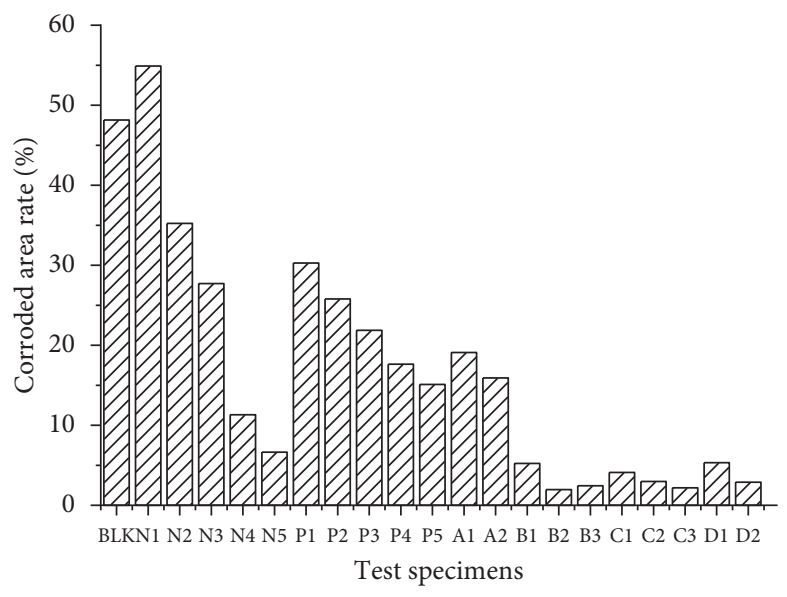

FIGURE 4: Corroded area rate of reinforcement.

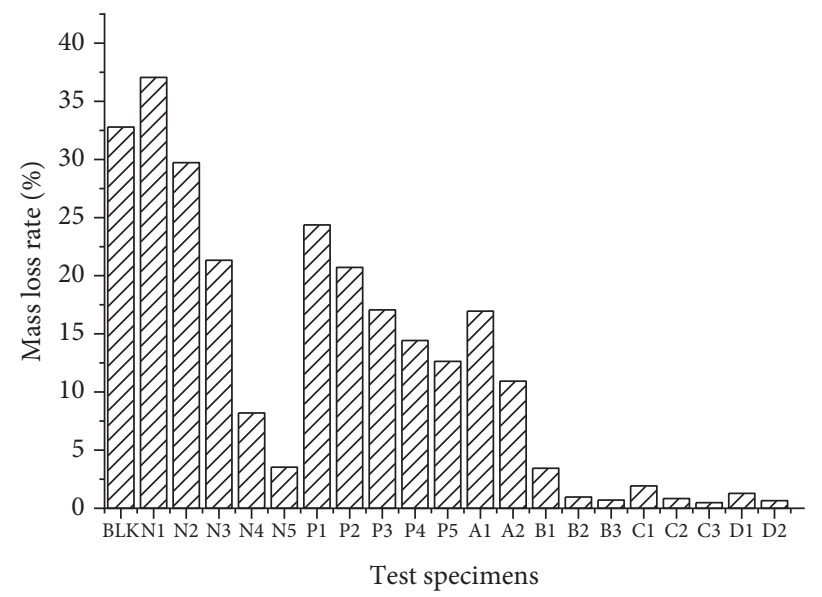

FIgURE 5: Mass loss rate of reinforcement.

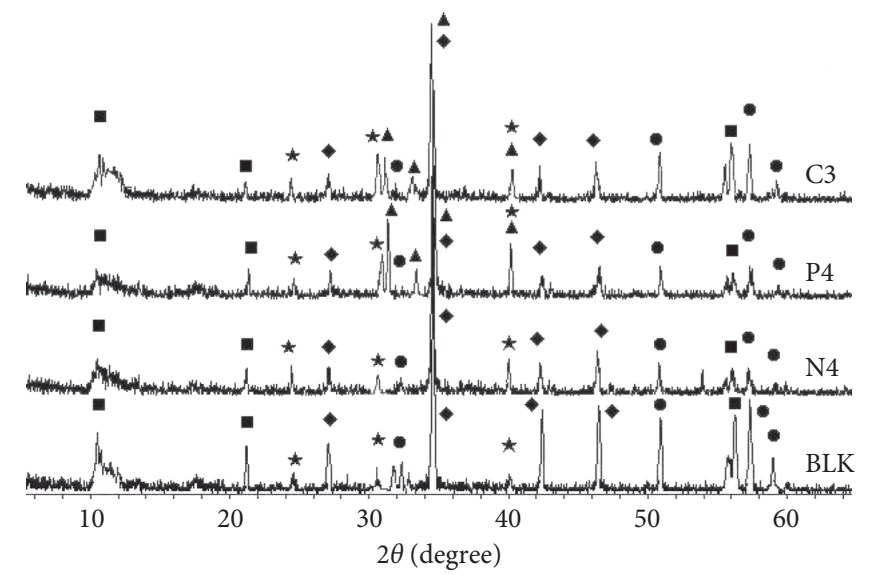

- $\mathrm{AFt}$

- $\mathrm{CaCO}_{3}$

- $\mathrm{CaSO}_{4} \cdot 2 \mathrm{H}_{2} \mathrm{O}$

$\star \mathrm{C}_{2} \mathrm{SHn}$

^ Calcium iron polyphosphate

FiguRE 6: X-ray diffraction pattern of cement. 
reference sample in the specimen with $\mathrm{NaNO}_{2}$, while the proportion of $\mathrm{C} 2 \mathrm{SHn}$ is significantly increased, which indicates that carbonation occurs in chloride-containing concrete, resulting in the consumption of $\mathrm{Ca}(\mathrm{OH})_{2}$ and C-S$\mathrm{H}$ in cement hydration products, and the penetration of ions is weakened by $\mathrm{NaNO}_{2}$. The diffraction peak intensity of $\mathrm{CaCO}_{3}, \mathrm{AFt}, \mathrm{CaSO}_{4} 2 \mathrm{H}_{2} \mathrm{O}$, and $\mathrm{C} 2 \mathrm{SH}$ are similar to those of $\mathrm{NaNO}_{2}$, except appearing calcium iron polyphosphate in the specimen with $\mathrm{Na}_{2} \mathrm{HPO}_{4}$. Literature $[30,31]$ shows that carbonation will consume $\mathrm{Ca}(\mathrm{OH})_{2}$ and reduce the $\mathrm{pH}$ in the pore solution of concrete. And, the $\mathrm{HPO}_{4}{ }^{2-}$ will increase with the decrease of $\mathrm{pH}$, combine with $\mathrm{Ca}^{2+}$ to form calcium phosphate colloid to move towards the cathode area of electrode reaction, and react with $\mathrm{Fe}^{3+}$ on the surface of the steel bar to form calcium ion polyphosphate precipitation to inhibit the corrosion process. In specimens with combined $\mathrm{NaNO}_{2}$ and $\mathrm{Na}_{2} \mathrm{HPO}_{4}$, the main diffraction peak of $\mathrm{CaCO}_{3}$, $\mathrm{AFt}, \mathrm{CaSO}_{4} 2 \mathrm{H}_{2} \mathrm{O}$, and $\mathrm{C}_{2} \mathrm{SHn}$ are higher than $\mathrm{N} 4$ and $\mathrm{P} 4$, and the diffraction peak intensity of calcium iron polyphosphate is lower than P4, indicating that nitrite oxidizes $\mathrm{Fe}^{3+}$ on the surface of steel bars in a dense passive film which reduces the corrosion area to decrease the contact probability between calcium phosphate and $\mathrm{Fe}^{3+}$, which proves the synergistic effect of $\mathrm{NaNO}_{2}$ and $\mathrm{Na}_{2} \mathrm{HPO}_{4}$. Therefore, the combination of $\mathrm{NaNO}_{2}$ and $\mathrm{Na}_{2} \mathrm{HPO}_{4}$ can achieve optimum corrosion resistance.

Figure 7 shows the $10 \mathrm{~K}$ electron microscope images of the specimens with no rust inhibitor, 2.0\% $\mathrm{NaNO}_{2}, 2.0 \%$ $\mathrm{Na}_{2} \mathrm{HPO}_{4}$, and combined 1.5\% $\mathrm{NaNO}_{2}$ and $1.5 \% \mathrm{Na}_{2} \mathrm{HPO}_{4}$. Figure (a) shows the concrete porosity is relatively large, and there are a few $\mathrm{Ca}(\mathrm{OH})_{2}$ crystals. In Figure $(\mathrm{b})$, the inside of concrete tends to be dense because $\mathrm{NaNO}_{2}$ can promote hydration, accelerate the formation of $\mathrm{Ca}(\mathrm{OH})_{2}$ crystals and calcium sulfoaluminate (AFt) crystals, and make the pores denser. From Figure (c), there are some interwoven flaky hydration products attached to the surface of the hardened cement paste to fill the internal pores of the concrete. This is mainly because phosphate can react with calcium hydroxide to form hydroxyapatite and deposit in the micropores of the cement stone, thereby enhancing the compactness of concrete. After compounding $1.5 \% \mathrm{NaNO}_{2}$ and $1.5 \% \mathrm{Na}_{2} \mathrm{HPO}_{4}$, the test piece is densely filled with various hydration products. A cathodic rust inhibitor, $\mathrm{HPO}_{4}{ }^{2-}$, produced by the hydrolysis of $\mathrm{Na}_{2} \mathrm{HPO}_{4}$ reacts with $\mathrm{Ca}^{2+}$ in the pore solution to form calcium phosphate colloidal particles and reacts with $\mathrm{Fe}^{2+}$ produced in the anode area to form a calcium iron phosphate precipitation film, which can prevent the water in the hole from moving inward. Therefore, $\mathrm{Na}_{2} \mathrm{HPO}_{4}$ can reduce the entry of harmful substances into the concrete, greatly extend the time for the chloride ion on the surface of the steel bar to reach the critical concentration, and improve the durability of the concrete.

\subsection{Corrosion Resistance Effect of Brushing, Perfusion, and} Compound Repair. Figure 8 shows the potential of steel bars after 12 months of brushing repair. The more the chloride ions, the lower the spontaneous potential and the more serious the corrosion of steel bars. The potential of each group is less than $-350 \mathrm{mV}$ after 6 months in blank group I, indicating that steel bars begin to corrode. During the period from 6th to 9th month, the potential decreases quickly, for the higher temperature and humidity would accelerate the corrosion of steel bars in summer. Comparing the test pieces after brushing of group E, it can be seen that the longer the repair time, the more obvious the potential rises and the better the corrosion resistance effect. When the proportion of $\mathrm{NaCl}$ is $0.01 \%$ and $0.03 \%$ of the sand quantity, the potential is relatively stable, illustrating that the brushing repair has a certain corrosion resistance effect. When the proportion of $\mathrm{NaCl}$ is $0.06 \%$ and $0.1 \%$ of the sand amount, the potential of the early and middle periods decreases rapidly and tends to be stable in the later period. This is because the lower concentration of sodium nitrite in the early stage will accelerate the corrosion of the steel bar. In the later stage, the effective corrosion resistance for the critical mole ratio of sodium nitrite is achieved, which plays a role in inhibiting corrosion.

Figure 9 shows the potential of steel bars after 12 months of perfusion repair. The $\mathrm{NaNO}_{2}$ and $\mathrm{Na}_{2} \mathrm{HPO}_{4}$ specimens with $150 \mathrm{ml}$ perfusion volume are named $\mathrm{F}$ and $\mathrm{G}$, and the blank control group is I. In group F, the potential in the early decreases clearly because of insufficient diffusion of $\mathrm{NaNO}_{2}$ in the early, resulting in a difference of concentration between the inside and outside of the perfusion radius, which causes macrocell corrosion and further serious pitting corrosion and accelerates the corrosion. However, the potential stabilizes and slightly increases in the latter, pointing that the $\mathrm{NaNO}_{2}$ on the surface of the steel bar is evenly distributed and reaches the critical molar ratio to inhibit further corrosion. Group G shows that the potential decreases in the early and middle periods and tends to be stable later, indicating it can suppress corrosion, but the effect is not as well as $\mathrm{NaNO}_{2}$. This is because phosphate, as a cathodic corrosion inhibitor, will react with calcium ions in the pore solution to form colloidal particles, which improves the compactness of concrete and adsorbs on the reinforcement to inhibit corrosion, which will not cause macrocell corrosion, but the efficiency is lower than nitrite.

Figure 10 shows the potential of steel bars after 12 months of composite repair. The specimens with $75 \mathrm{ml}$ of $\mathrm{NaNO}_{2}$ and $75 \mathrm{ml}$ of $\mathrm{Na}_{2} \mathrm{HPO}_{4}$ are named $\mathrm{H}$. It can be seen that compared with the other two repair methods, the potential of the composite repaired specimens decreases more stably and tends to be stable in the latter. And the final potential is higher than that of brushing or perfusion repair. Therefore, the composite repair has not only excellent corrosion resistance effect but also will not cause macrocell corrosion and aggravate the corrosion of steel bar, which has a bright application prospect.

3.4. Repair Effect of Existing Concrete Structure. For marine concrete structures, the critical concentration of chloride in steel bars rusted of concrete is from $0.07 \%$ to $0.18 \%$. The internal steel bars of concrete have corroded when the chloride content is more than $0.05 \%$ [32]. The average chloride concentration in the existing concrete structure is 


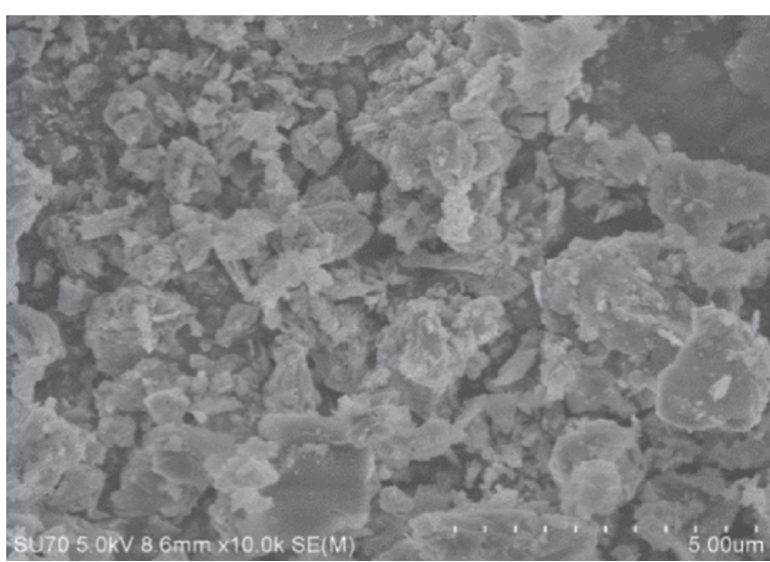

(a)

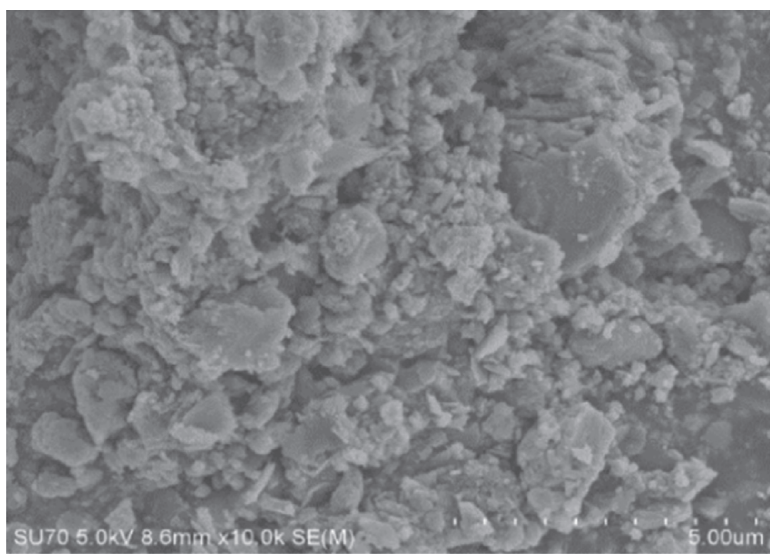

(c)

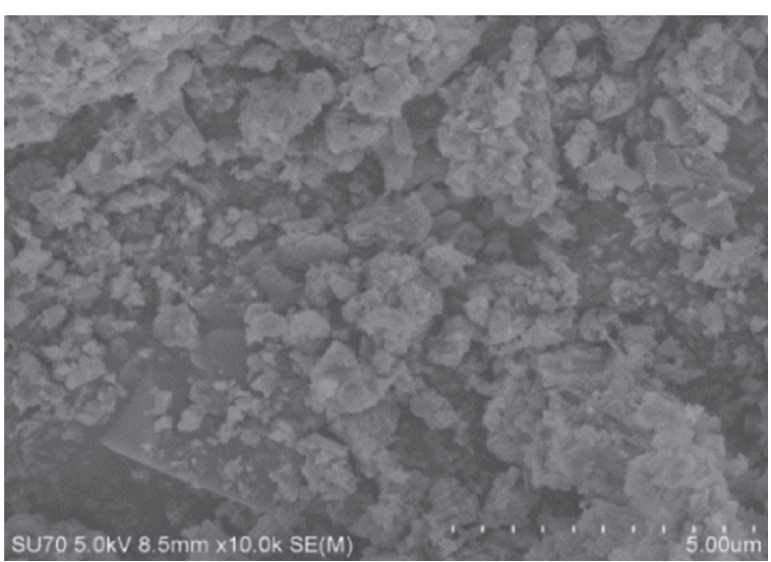

(b)

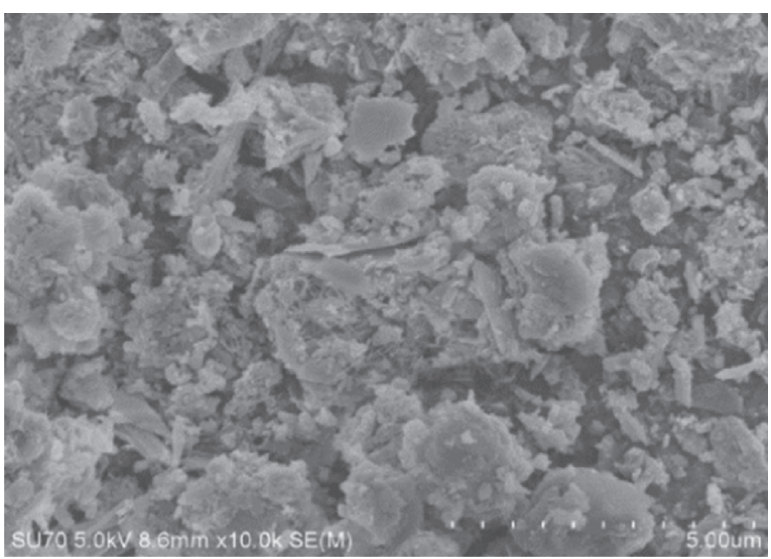

(d)

FIGURE 7: SEM of cement paste with different corrosion inhibitors.

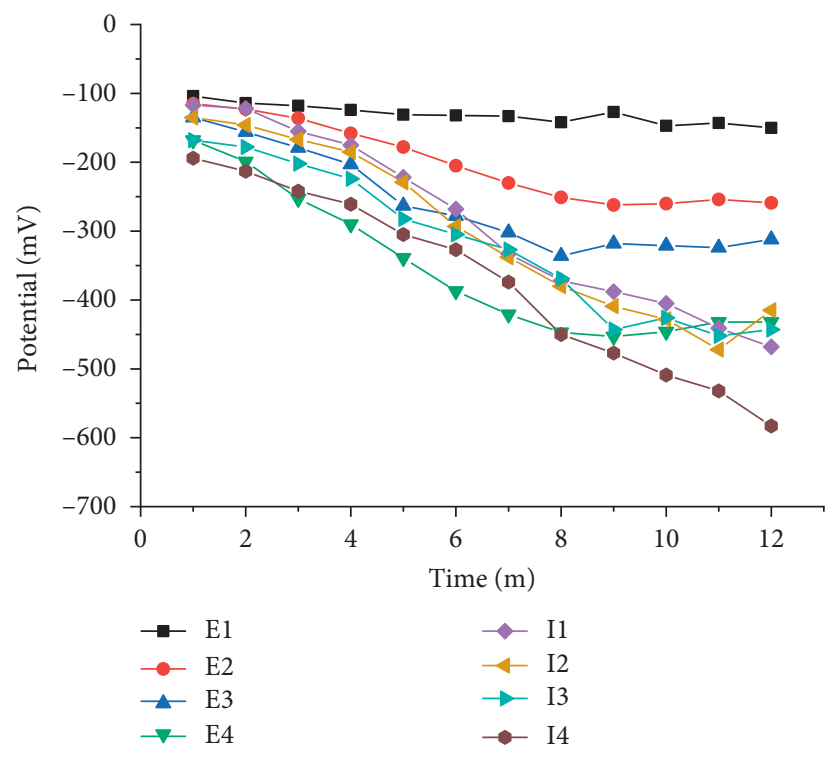

Figure 8: Potential of brushing repair. 


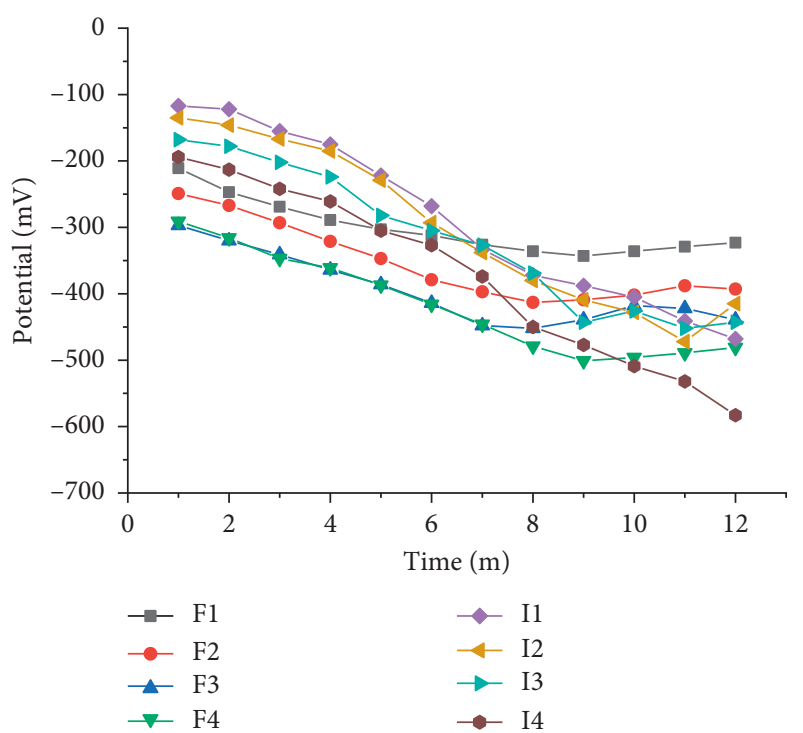

(a)

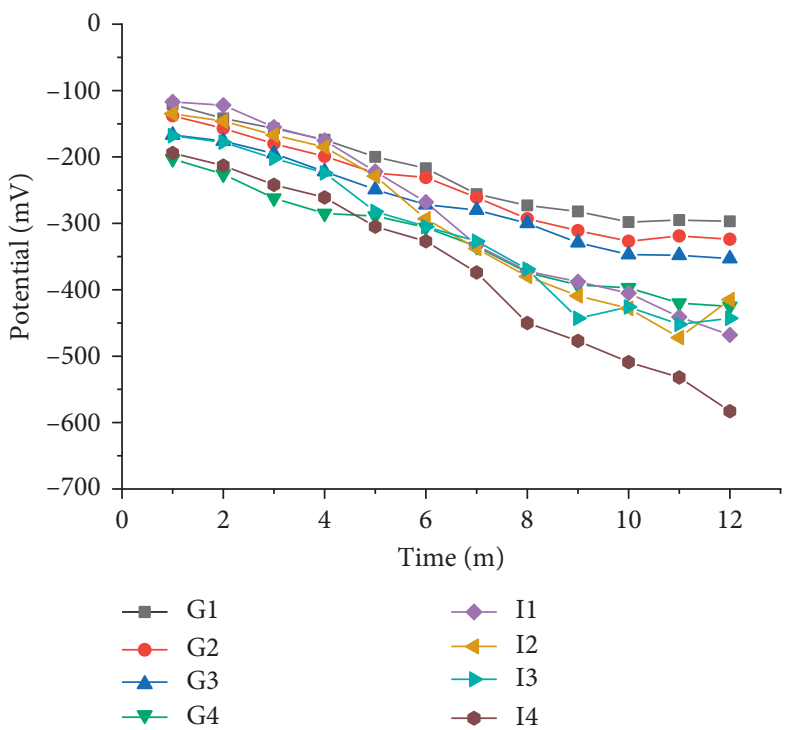

(b)

Figure 9: Potential of composite repair. (a) Potential of group F and group I. (b) Potential of group G and group I.

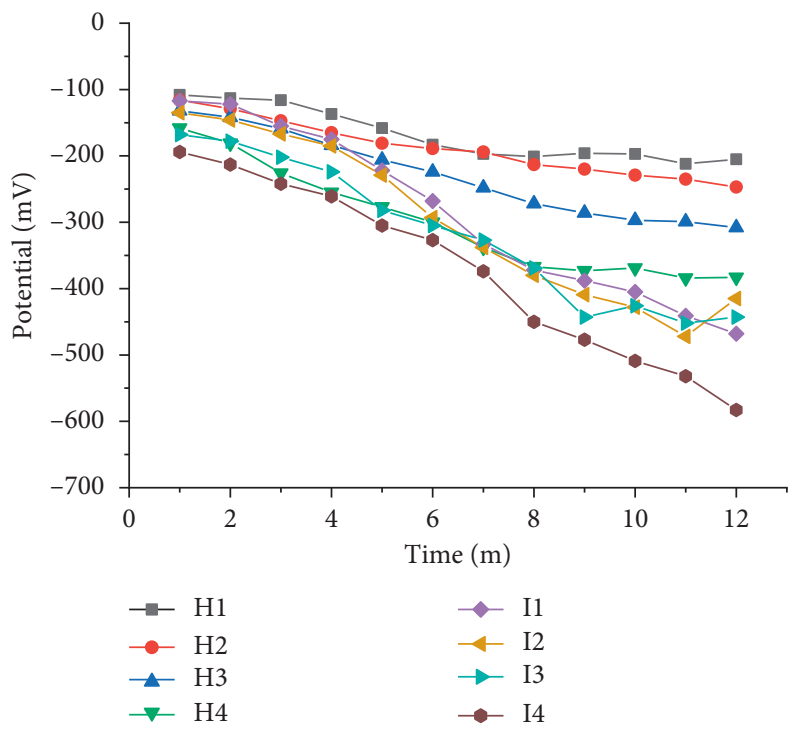

Figure 10: Potential of composite repair.

more than $0.05 \%$ through measurement, indicating that the corrosion caused by chloride in the concrete is the main reason affecting the durability of the structure.

Two areas of $1500 \mathrm{~mm} \times 1500 \mathrm{~mm}$ are repaired by brushing repair and composite repair, respectively. Figures 11 and 12 show the potential and corrosion current of reinforcement measured every 90 days. It can be seen that, in the existing concrete structure, the repair effect is similar to the results of concrete specimens mixed with chloride. Through brushing sodium nitrite, the potential rises from $-360 \mathrm{mV}$ to $-207 \mathrm{mV}$, while the corrosion current decreases from $0.627 \mu \mathrm{A} / \mathrm{cm}^{2}$ to $0.374 \mu \mathrm{A} / \mathrm{cm}^{2}$, which illustrates that the probability of corrosion is significantly reduced. The effect of corrosion resistance is more significant in composite repair. The potential rises from $-385 \mathrm{mV}$ to $-193 \mathrm{mV}$, and the corrosion current decreases from $0.653 \mu \mathrm{A} / \mathrm{cm}^{2}$ to $0.287 \mu \mathrm{A} / \mathrm{cm}^{2}$. The corrosion current of more than $96 \%$ area is less than $0.5 \mu \mathrm{A} / \mathrm{cm}^{2}$, and the corrosion probability of reinforcement has been decreased from $90 \%$ to only $5 \%$ in most areas after 6 months. The potential and corrosion current of the lower part of the structure is always higher than that of the upper part, for the lower part of the repaired structure is a wave washing area and the influence of seawater erosion and the long-term dry wet cycle will increase the chloride content. It can conclude that composite repair can greatly reduce the probability of steel bar corrosion and 

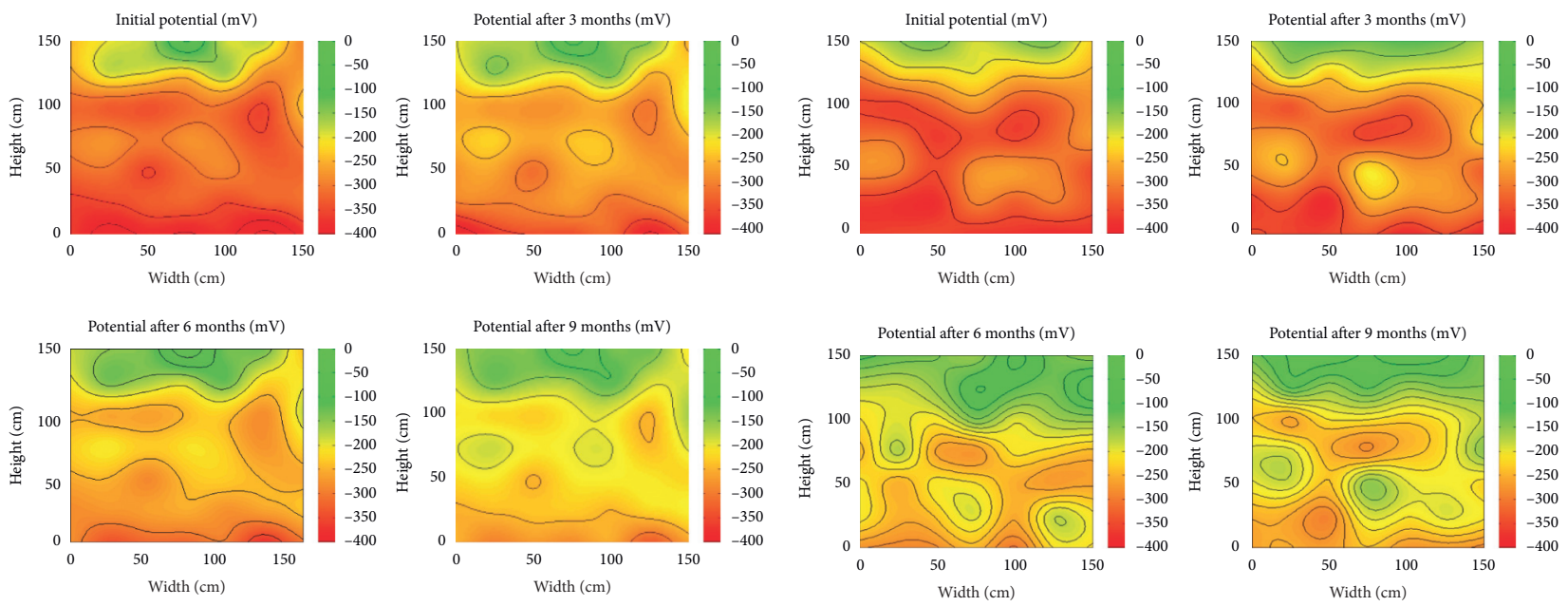

(a)

(b)

Figure 11: Potential of rebar in existing concrete. (a) Potential of brushing repair. (b) Potential of composite repair.
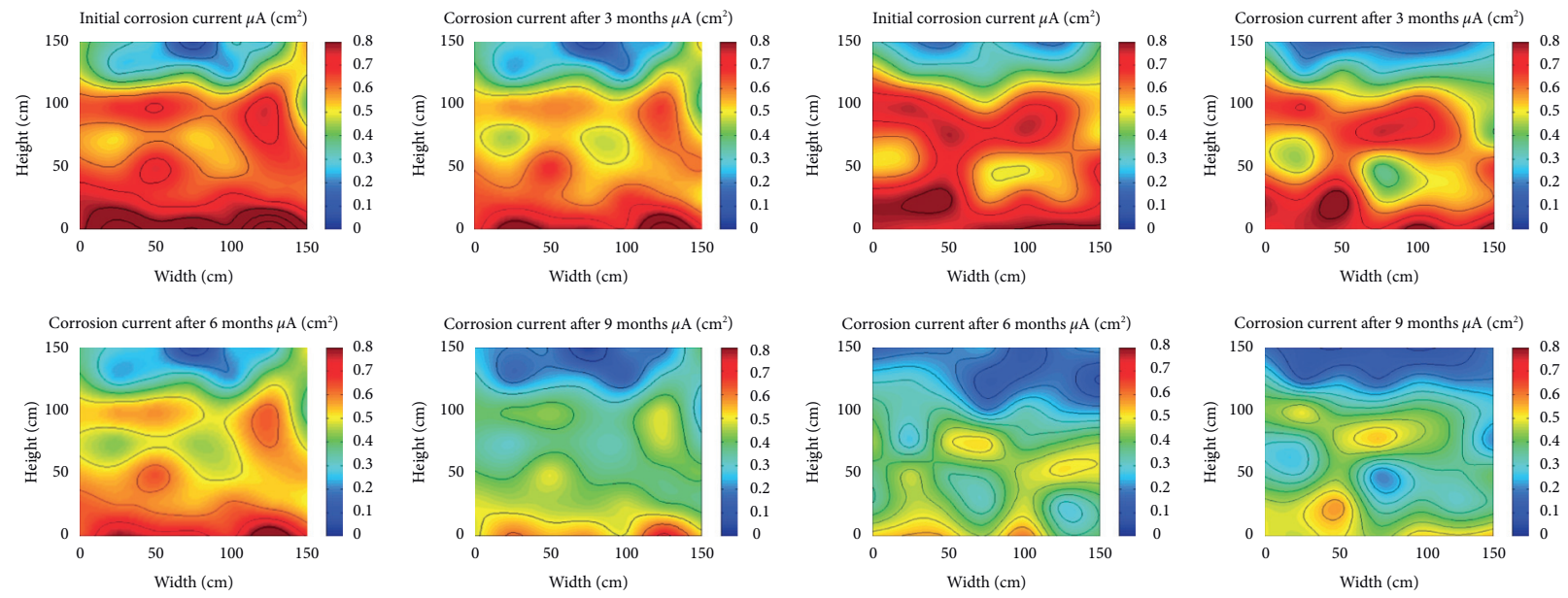

(a)

(b)

FIGURE 12: Corrosion current of rebar in existing concrete. (a) Corrosion current of brushing repair. (b) Corrosion current of composite repair.

greatly improve the durability of engineering structures, which has a good prospect of engineering application.

\section{Conclusions}

The following conclusions are derived from this study:

(1) Nitrite has a better inhibitory effect than phosphate, and when the respective mass fraction of hydrogen phosphate and sodium nitrite is about $1.5 \%$, the corrosion area and weight loss rate can be greatly improved, and the corrosion resistance is the optimum

(2) Brushing, perfusion, and composite repair can all play a good role in inhibiting corrosion, of which composite repair is the optimum
(3) The addition of phosphate can effectively improve the macrocell corrosion caused by the low dosage or uneven distribution of nitrite

\section{Data Availability}

The data used to support the findings of this study are available from the corresponding author upon request.

\section{Conflicts of Interest}

The authors declare that there are no conflicts of interest regarding the publication of this paper. 


\section{Acknowledgments}

This work was sponsored by the National Natural Science Foundation of China (51778302 and 51878360) and Ningbo Science and Technology Project (202002N3117 and 202003N4136).

\section{References}

[1] Y. Gao, L. Qu, B. He, K. Dai, Z. Fang, and R. Zhu, "Study on effectiveness of anti-icing and deicing performance of superhydrophobic asphalt concrete," Construction and Building Materials, vol. 191, pp. 270-280, 2018.

[2] C. Liang, H. Ma, Y. Pan, Z. Ma, Z. Duan, and Z. He, "Chloride permeability and the caused steel corrosion in the concrete with carbonated recycled aggregate," Construction and Building Materials, vol. 218, pp. 506-518, 2019.

[3] J. Yang, J. Huang, Y. Su et al., "Eco-friendly treatment of lowcalcium coal fly ash for high pozzolanic reactivity: a step towards waste utilization in sustainable building material," Journal of Cleaner Production, vol. 238, 2019.

[4] H. Wang, X. Gao, and J. Liu, "Effects of salt freeze-thaw cycles and cyclic loading on the piezoresistive properties of carbon nanofibers mortar," Construction and Building Materials, vol. 177, no. 20, pp. 192-201, 2018.

[5] R. Z. Dong and Y. Gao, "Transport state of chloride ion in concrete crack area under dry-wet cycle," Bulletin of the Chinese Ceramic Society, vol. 36, no. 4, pp. 1113-1119, 2017.

[6] Y. Kang and G. Li, "Corrosion behavior of reinforced bar in concrete in marine environment," Tunnel Construction, vol. 38, no. 12, pp. 1966-1974, 2018.

[7] C. M. Zhong, Z. M. Shao, H. Q. Gao et al., "Discussion on technical issues for application of nitrite corrosion inhibitor," Concrete, vol. 12, pp. 46-51, 2009.

[8] S. H. Ma, W. H. Li, H. B. Zheng et al., "Research progress of anti-corrosion mechanism and performance evaluation of corrosion inhibitor for steel bar," Corrosion and Protection, vol. 38, no. 12, pp. 963-968, 2017.

[9] J. O. Okeniyi, O. A. Omotosho, O. O. Ajayi, and C. A. Loto, "Effect of potassium-chromate and sodium-nitrite on concrete steel-rebar degradation in sulphate and saline media," Construction and Building Materials, vol. 50, pp. 448-456, 2014.

[10] Z. Malaibari, R. Kahraman, and A. Rauf, "Corrosion of inhibitor treated mild steel immersed in distilled water and a simulated salt solution," Anti-Corrosion Methods and Materials, vol. 60, no. 5, pp. 227-233, 2013.

[11] J. Xia, X. Cheng, Q.-f. Liu et al., "Effect of the stirrup on the transport of chloride ions during electrochemical chloride removal in concrete structures," Construction and Building Materials, vol. 250, Article ID 118898, 2020.

[12] L.-x. Mao, Z. Hu, J. Xia et al., "Multi-phase modelling of electrochemical rehabilitation for ASR and chloride affected concrete composites," Composite Structures, vol. 207, pp. 176-189, 2019.

[13] W. Yeih, J. J. Chang, C. C. Chang, K. L. Chen, and M. C. Chi, "Electrochemical chloride removal for reinforced concrete with steel rebar cage using auxiliary electrodes," Cement and Concrete Composites, vol. 74, pp. 136-146, 2016.

[14] M. B. Valcarce and M. Vázquez, "Carbon steel passivity examined in solutions with a low degree of carbonation: the effect of chloride and nitrite ions," Materials Chemistry and Physics, vol. 115, no. 1, pp. 313-321, 2009.
[15] Y. M. Tang, B. Niu, B. Lin et al., "Inhibitor effect of $\mathrm{NO}_{2}{ }^{-}$and its concentration on metastable pitting in a simulated concrete pore solution," Caorrosion Science and Protection Technology, vol. 27, no. 2, pp. 123-128, 2015.

[16] Z. Y. Ai and X. P. Shu, "Review on the research and application progress of concrete reinforcement corrosion prevention technology," Materials Protection, vol. 53, no. 9, pp. 107-132, 2020.

[17] J. Z. Liu, W. Sun, Z. M. He et al., "Corrosion inhibition of nitrite salt in existing reinforced concrete structures," Journal of The Chinese Ceramic Society, vol. 42, no. 5, pp. 607-612, 2014.

[18] Y. J. Chen, L. H. Jiang, X. C. Yan et al., "Impact of phosphate corrosion inhibitors on chloride binding and release in cement pastes," Construction and Building Materials, vol. 236, 2020.

[19] H. W. Zhu, H. F. Yu, and H. Y. Ma, "Electrochemical study on the influence of rust inhibitors on the corrosion of steel bars in concrete in marine environment," Journal of Southeast University, vol. 50, no. 1, pp. 109-119, 2020.

[20] H. B. Mansour, L. Dhouibi, and H. Idrissi, "Effect of Phosphate-based inhibitor on prestressing tendons corrosion in simulated concrete pore solution contaminated by chloride ions," Construction and Building Materials, vol. 171, no. 2, pp. 250-260, 2018.

[21] V. T. Ngala, C. L. Page, and M. M. Page, "Corrosion inhibitor systems for remedial treatment of reinforced concrete. part 2: sodium monofluorophosphate," Corrosion Science, vol. 45, no. 7, pp. 1523-1537, 2003.

[22] Y. Tang, S. Wang, Y. Xu, and J. Ni, "Influence of calcium nitrite on the passive films of rebar in simulated concrete pore solution," Anti-Corrosion Methods and Materials, vol. 64, no. 3, pp. 265-272, 2017.

[23] J. J. Shi and W. Sun, "Effects of phosphate on the chlorideinduced corrosion behavior of reinforcing steel in mortars," Cement and Concrete Composites, vol. 45, pp. 166-175, 2014.

[24] N. Etteyeb, L. Dhouibi, H. Takenouti, and E. Triki, "Protection of reinforcement steel corrosion by phenylphosphonic acid pre-treatment part II: tests in mortar medium," Cement and Concrete Composites, vol. 65, no. 3, pp. 94-100, 2016.

[25] J. Z. Liu, F. Xing, Z. M. He et al., "Critical mole ratios of nitrite and chloride in reinforced concrete," Journal of The Chinese Ceramic Society, vol. 38, no. 4, pp. 615-620, 2010.

[26] H. Verbruggen, H. Terryn, and I. De Graeve, "Inhibitor evaluation in different simulated concrete pore solution for the protection of steel rebars," Construction and Building Materials, vol. 124, pp. 887-896, 2016.

[27] B. Assouli, G. Ballivy, and P. Rivard, "Influence of environmental parameters on application of standard ASTM C87691: half cell potential measurements," Corrosion Engineering, Science and Technology, vol. 43, no. 1, pp. 93-96, 2013.

[28] J. Liu, J. Geng, H. Wang, M. Ba, and Z. He, "Influence of nitrite on chemical composition of passivation film of steel bars under the coupling effects of carbonization and chloride," Anti-Corrosion Methods and Materials, vol. 66, no. 2, pp. 230-235, 2019.

[29] M. S. Chen, C. T. Sun, and J. F. Yu, "Mechanism of corrosion inhibitor in concrete orrosion-resistant," Concrete, vol. 6, pp. 80-83, 2015.

[30] W. Shi, T.-Z. Wang, Z.-H. Dong, and X.-P. Guo, "Application of wire beam electrode technique to investigate the migrating behavior of corrosion inhibitors in mortar," Construction and Building Materials, vol. 134, pp. 167-175, 2017. 
[31] D. M. Bastidas, M. Criado, V. M. La Iglesia, S. Fajardo, A. La Iglesia, and J. M. Bastidas, "Comparative study of three sodium phosphates as corrosion inhibitors for steel reinforcements," Cement and Concrete Composites, vol. 43, pp. 31-38, 2013.

[32] S. Pradelle, M. Thiéry, and V. Baroghel-Bouny, "Sensitivity analysis of chloride ingress models: case of concretes immersed in seawater," Construction and Building Materials, vol. 136, pp. 44-56, 2017. 